\title{
Many Voices in the Room: A National Survey Experiment on How Framing Changes Views Toward Fracking in the United States*
}

\author{
Patrick Bayer $^{\dagger} \quad$ Alexander Ovodenko ${ }^{\ddagger}$
}

May 29, 2019

\begin{abstract}
Hydraulic fracturing (or "fracking") is one of the most controversial energy production processes in the United States and globally. In democracies, maintaining energy policy on politically salient and controversial issues, such as the use of fracking, depends on popular support at local if not national levels. We therefore study the effectiveness of widely cited arguments about fracking in a representative sample of the United States. Consistent with framing theory, we find that arguments that emphasize the environmental costs of fracking drive down support, while arguments emphasizing job creation and energy security increase it. However, we also show that presenting competing information from pro-fracking and anti-fracking frames together neutralizes individual framing effects, albeit not for every combination of frames and counter-frames. Framing effects become stronger when arguments, particularly about water contamination, are congruent with respondents' pre-existing beliefs, which may lead to further polarization in the public debate. The exact kinds of arguments and how they are paired with one another do matter - a finding that is relevant for our understanding of public opinion on climate change and renewable energy policy more broadly.
\end{abstract}

Keywords: fracking; hydraulic fracturing; shale gas; survey experiment; framing; public opinion.

\footnotetext{
${ }^{*}$ We acknowledge funding from the Resources for the Future John V. Krutilla Research Stipend and thank the Department of Political Science at Washington University in St. Louis for their hospitality. We are particularly indebted to Betsy Sinclair and Patrick Tucker for their support with data collection through The American Panel Survey (TAPS) and thank Paasha Mahdavi and Johannes Urpelainen for comments on previous drafts. We are also grateful to the Editor of Energy Research \& Social Science, Benjamin Sovacool, and three anonymous reviewers for their helpful and incisive comments and feedback. All errors are our own.

${ }^{\dagger}$ University of Strathclyde. School of Government \& Public Policy, McCance Building, 16 Richmond Street, Glasgow, G1 1QX, Scotland, UK. Email: patrick.bayer@strath.ac.uk

${ }^{\ddagger}$ Corresponding author. Georgetown University. Mortara Center for International Studies, 3600 N Street NW, Washington, D.C. 20007, USA. Email: ao690@georgetown.edu
} 


\section{Introduction}

Addressing climate change will require governments to take strong domestic action. More specifically, facilitating a low-carbon transition in industrialized economies will require energy policy that incentivizes the integration of new technologies (IPCC, 2018). In democratic countries, energy policy can only be effective if it is politically feasible, which generally entails some popular support and a coalition of business or industry support. Public opinion is one factor among several that affects the ambition of energy policies related to climate change (Hughes and Urpelainen, 2015). Although industry support is critical, energy policy that does not respect public opinion has the potential to trigger mass protests and political unrest, with recent demonstrations and violence in France over high fuel levies offering one example. ${ }^{1}$ Fracking has been controversial, not only in the United States but also the United Kingdom (Whitton et al., 2017). Some states in the US and some councils in the UK have banned fracking amid public protests, ${ }^{2}$ offering an ideal situation in which to study the effects of different arguments about energy production when issue salience is high amongst the public.

In this paper, we use the contentious debate surrounding hydraulic fracturing, or "fracking," to study how information on the environmental costs and economic benefits affect public opinion on the issue. While we focus on the United States, which has seen unprecedented growth in fracking since the mid-2000s (Christenson, Goldfarb, and Krinera, 2017), our findings have implications for the ongoing debate about fracking in the United Kingdom as well. Clearly, framing an issue in exclusively positive light helps build support, whereas portraying it negatively generates opposition. However, what happens when both the fossil fuel industry and environmental groups seek to frame an issue, such as fracking, on their own terms? To answer this question, our main innovation comes from examining public opinion on fracking when we combine the most prominent arguments by fracking supporters and their opponents. We do not use generic statements about the opportunities and threats from fracking, but pay careful attention to the role of distinctive arguments. While we do not develop a new theory, we extend arguments from the framing literature to understand how

\footnotetext{
1 "Paris Riots: PM to Meet Protest Groups after Worst Unrest in Decade." The Guardian 3 December 2018.

2 "Local Councils Heading for Fracking Showdown with Government." The Guardian 4 January 2019.
} 
a saturated informational environment influences public opinion on fracking.

We focus on fracking for a number of reasons. First, it is a major political issue in the United States that is salient because of significant local and national consequences. In particular, fracking raises NIMBY issues at local and state levels but also the prospects of economic revival in postindustrial or rural communities (Davis and Fisk, 2014). Second, it is ripe for analyzing framing effects when people have varying levels of knowledge and understanding of the issue and varying levels of opinion intensity. Fracking is different from many other policy issues because of the unique combination of pre-existing knowledge and multi-level distributional consequences.

Regarding the politics of fracking, energy policy was a prominent topic in the 2016 U.S. presidential race and became enmeshed in the overarching public discussions of jobs creation, economic revival, and trade policy. As a Republican candidate, Donald Trump promoted an agenda of "energy dominance," calling for maximizing economic output from fossil fuels. U.S. voters were exposed to competing arguments about energy resources as economic opportunities and pollution sources. ${ }^{3}$ Nonetheless, how voters weighed the relative benefits and costs from fracking remains unclear.

The tremendous increase in natural gas and oil production from horizontal drilling and hydraulic fracturing, often known as the "shale revolution" 4 , has reduced energy prices in the U.S., increased exports of liquefied natural gas and oil, and promoted employment in large parts of the country (Feyrer, Mansur, and Sacerdote, 2017; Cosgrove et al., 2015; Weber, 2012). Despite these benefits, fracking carries serious risks to the environment and public health. It has been associated with contaminated drinking water, earthquakes, and it increases reliance on fossil fuels (Llewellyn et al., 2015; Krupnick and Gordon, 2015; Jackson et al., 2014; Israel et al., 2015). It may also lead to methane leaks from wells that exacerbate climate change (Tollefson, 2013). We study how these different risks and opportunities - formulated as distinct arguments rather than generic statements - affect public opinion by mimicking the 'real world' information and media

\footnotetext{
3 "Trump's 'Energy Dominance' Doctrine Is Undermined by Climate Change," The New York Times 29 November 2018

${ }^{4}$ Natural gas production from fracking increased almost fifteen-fold from 3.6 billion cubic feet per day (Bcf/d) in 2000 to $53 \mathrm{Bcf} / \mathrm{d}$ in 2015. Oil production from fracking grew from 102,000 barrels/day to more than 4.3 million barrels/day over the same years (U.S. Energy Information Administration, 2016a,b).
} 
environment on fracking in a controlled experiment (Gearhart, Adegbola, and Huemmer, 2019).

Providing the respondents in our study with competing information matches the polarization of policy debates in the United States and the United Kingdom, including on fracking (Cooper, Kim, and Urpelainen, 2018). U.S. states have adopted different policies toward fracking, ranging from favorable regulation in Colorado, Pennsylvania, and Texas, to an outright ban in New York (Davis, 2012; Rabe and Borick, 2013; Rinfret, Cook, and Pautz, 2014). Similarly, the United Kingdom had initially banned fracking because drilling at its initial stage of development had caused small tremors (Whitton et al., 2017). After halting operations for seven years, Cuadrilla Resources, the company originally undertaking the drilling, started exploratory operations in northwest England as recently as October $2018 .{ }^{5}$ While the UK government seems to be in favor of fracking, adding to the country's domestic energy supply, environmental groups seek to stop fracking before it starts and are getting support lately by local councils in the Greater Manchester area. ${ }^{6}$

We conducted a two-stage survey experiment on fracking with a nationally representative sample in the United States, where we exposed respondents to different information, or "issue frames" (Chong and Druckman, 2007b), about fracking. We used a full factorial design of the most prominent arguments opposed to or in favor of fracking. On the risks from fracking, we focused (i) on the possibility of water contamination; (ii) uncertain consequences from fracking, including earthquakes; and (iii) the diversion of investment away from renewables. Regarding the benefits of fracking, we focused on job creation and increased energy security. Importantly, our research design allowed us to assess how public support changes when respondents receive both single and competitive frames. The latter is the norm in democratic, public debates (Druckman, 2004; Chong and Druckman, 2007a) and thus resembles how people are exposed to information on politically contested issues in everyday life.

Our first set of results is consistent with framing theory in that presenting respondents with a single anti-fracking frame decreases support, while pro-fracking frames increase support. This is consistent with findings by others on clean energy (Aklin and Urpelainen, 2013; Stokes and

\footnotetext{
5 "It Once Caused Earthquakes. Now a Driller in Britain Tries Fracking Again." The New York Times, 11 October 2018.

6 "Fracking to be formally Opposed by all Greater Manchester Town Halls." Manchester Evening News 4 January 2019 .
} 
Warshaw, 2017) and climate policy (Bernauer and McGrath, 2016). What is surprising, however, is that even in an informationally saturated environment, where arguments about fracking are out in the open, we find public opinion to still be malleable. Even more importantly, we find that counter-frames can neutralize the effects of single frames. Once the treatment presents competing information - that is, pro-fracking and anti-fracking arguments are presented together - the framing effects cancel each other out in most cases (Chong and Druckman, 2013; Aklin and Urpelainen, 2013; Christenson, Goldfarb, and Krinera, 2017). An important contribution of our work, both theoretically and empirically, is to show that these neutralizing effects do not happen uniformly for all combinations of pro-fracking and anti-fracking arguments. Rather, the exact substance of frames and counter-frames matters.

The second set of results is about how fracking knowledge and information shape framing effects. We do not find any evidence that better fracking knowledge conditions our main results. Yet, there is tentative evidence that familiarity with specific arguments, mostly the concern about water quality, can amplify framing effects. This effect is strongest for congruent information. More specifically, respondents who already hold the (pre-treatment) belief that fracking contaminates drinking water tend to support fracking much less when they receive the water treatment relative to those who only receive that treatment. Frames that emphasize arguments that cohere with a person's viewpoint or beliefs on fracking can harden those views and trigger a stronger response. Even though these findings are preliminary, they call for a better understanding of how pre-existing knowledge and beliefs affect framing effects from different fracking arguments.

These findings have important implications for public opinion on fracking, in particular, and energy policy, more broadly, because they imply that in informationally saturated environments, simply providing any information is unlikely to change people's views. The neutralizing effect of frames and counter-frames solidifies the political status quo in a polarized informational environment (Gearhart, Adegbola, and Huemmer, 2019). On polarized political issues that generate benefits for some but costs for others, as in a country's energy transition, targeted information will be needed to build popular support for the policy in question. This makes a case for local and state-level political messaging in the debate over fracking (Evensen and Brown-Steiner, 2018; 
Howell et al., 2017), although we acknowledge that popular support alone does not ensure that an energy policy will be adopted and sustained.

\section{Public support for fracking: Issue framing and hypotheses}

Several studies in political communication have shown that people generally respond to framing effects, although the impact varies (e.g., Druckman, 2004; Chong and Druckman, 2007a). For example, Druckman $(2004,672)$ refers to framing as "situations where, by emphasizing a subset of potentially relevant considerations, a speaker leads individuals to focus on these considerations when constructing their opinions." This implies that by providing individuals with some information and excluding other information, public opinion can shift. In studying energy politics, Stokes and Warshaw (2017) demonstrate the importance of framing effects in building support for renewable energy policy in the United States. Similarly, Christenson, Goldfarb, and Krinera (2017) show that emphasizing positive effects from fracking increases support for it. Our first hypothesis applies this framing logic in a straightforward way to fracking.

Hypothesis 1 (Single frame). A single frame presenting benefits (costs) from fracking increases (decreases) popular support for fracking.

While we would expect that supporting and opposing arguments on fracking would shift support in the corresponding direction, the wider public debate over fracking is filled with competing claims. On controversial issues, voters are usually exposed to different viewpoints in advance of voting for a candidate for public office or a referendum. In the case of fracking, environmental groups warn of the environmental consequences of the policy, while fossil fuel companies highlight the economic opportunities. Hence, in reality, frames are rarely, if ever, presented in isolation to the public, but rather in conjunction with opposing counter-arguments- "counter-frames" (Chong and Druckman, 2013). Counter-frames can be powerful communication strategies to neutralize public information effects in energy politics (Aklin and Urpelainen, 2013; Christenson, Goldfarb, and Krinera, 2017). We formulate the following hypothesis on counter-frames in the debate over fracking:

Hypothesis 2 (Counter-frames). Combining a single frame presenting benefits (costs) from frack- 
ing with a competing frame presenting costs (benefits) does not change popular support for fracking.

A major strength of our research design is that we use substantively different arguments about fracking. Our experimental frames are not presented as generic statements that fracking can be associated with benefits and costs. In particular, we present the most widely discussed benefits and risks associated with fracking in the experimental conditions, having used a pre-test of nearly ten different arguments before adopting the most powerful ones for and against fracking based on the pre-tests. In fact, each framing of fracking that made it into the experiment was based on public statements, research studies, or news coverage of fracking. The source of the information was made clear to the study participants, making the statements appear more credible and transparent. By drawing on a set of specific arguments relevant to fracking (Hilson, 2015), we can analyze the relative effectiveness of frames and counter-frames in a more nuanced way, as we are able to assess the comparative effectiveness of specific pro- and anti-fracking arguments when presented independently and jointly in all possible combinations.

Based on the framing literature, we theorize that people respond to information about fracking differently depending on their prior knowledge of the issue. Previous research has shown that not everyone is equally likely to respond to framing effects because of prior knowledge and belief structures. Information and knowledge, or what Druckman (2004) calls "expertise," of a given topic should condition the effectiveness of issue framing. Boudet et al. (2014) show that better knowledge of fracking decreases support for it, while knowledge also moderates the relationship between party ideology and fracking support in the United States (Choma, Hanoch, and Curriea, 2016). The persistence of framing effects, more broadly, also depends on prior knowledge (Lecheler and de Vreese, 2011). Our study adds to this literature by highlighting how prior knowledge conditions the effectiveness of specific arguments about fracking. How informed or knowledgeable people are about fracking should affect how effectively public opinion can be changed, even when the general public is fairly well informed. We formalize this theoretical expectation in the following hypothesis.

Hypothesis 3 (Interaction: prior knowledge). The effectiveness of a single frame decreases with better knowledge of fracking.

Framing operates through an informational channel. It changes what people know about a 
subject and that triggers a response in opinion. When abundant information is publicly available or many viewpoints are publicly discussed, framing effects may not occur purely because new information is presented in the frames. Rather, the information provided is used to confirm existing opinions and beliefs that respondents hold. Chong and Druckman (2007a) show that this valuecongruent information boosts the strength of framing effects. In our example, respondents may already be aware that fracking might trigger earthquakes. Receiving an "earthquake" frame does not convey new information, but it may harden existing beliefs. We therefore expect that presenting arguments that are congruent with pre-existing knowledge amplify framing effects. Confirmatory frames function like a repetition of an individual's original opinion. This strengthens prior viewpoints and may lead to polarization for divisive and salient issues. Our final hypothesis - potentially the most critical one from a political communication standpoint - captures this logic.

Hypothesis 4 (Interaction: information congruence). The effectiveness of a frame grows when the frame presents an argument that is congruent with an individual's original understanding of the issue.

The two interaction hypotheses apply insights from the framing literature to the issue of fracking. We thereby extend these arguments not only to an important issue in energy policy but also test how prior knowledge and congruent information affect framing effects on fracking.

\section{$3 \quad$ Experimental design}

This section describes the experimental design of our study, which conforms to most of the recommendations for rigorous social scientific analysis of energy policy (Sovacool, Axsen, and Sorrell, 2018). The study offers two main innovations compared to other survey experimental work. First, taking advantage of the fact that our experiment was implemented as part of a representative panel study, our data collection occurred in two stages - a pre-experiment survey in January 2016 (sample size: $n=1,704$ ) and the main survey experiment in April 2016 (sample size: $n=1,668$ ). This allows our research design to leverage the 'longitudinal' aspect of views toward fracking and ensures that we can collect respondent attributes strictly before the treatment was administered, thus 
avoiding any bias from the experiment. Second, as mentioned above, we used a full factorial design of all combinations of single frames and counter-frames of the five most powerful environmental and economic arguments in favor of and against fracking, based on a pre-test using Amazon's Mechanical Turk that involved a wider selection of "candidate" frames. This pre-test employed a convenience sample before the pre-experiment and experiment surveys used randomized nation-wide samples.

The pre-experiment survey and the main experiment were embedded in regular monthly iterations of "The American Panel Survey" (TAPS, 2016). ${ }^{7}$ TAPS draws on a national probability sample of roughly 2,000 respondents across the United States and keeps panel retention high by regularly replenishing the pool of respondents. In our case, the attrition rate between the January and April waves was only 2.1\%. The TAPS panel of respondents is further closely matched to Current Population Survey estimates of the American population on key demographic characteristics. We are confident that the sample from TAPS is broadly representative, which according to Miratrix et al. (2018) justifies estimating sample average treatment effects without applying survey weights. Furthermore, this helps us to avoid losing statistical power from using survey weights.

\subsection{Pre-experiment}

We conducted a pre-experiment survey to ensure that all basic covariate information and respondents' views on fracking were collected pre-treatment. By spreading out pre-experimental questions and the experiment over time, we can rule out undesirable confounding or priming effects. Asking respondents about their fracking support, for example, could change how they respond to a treatment that follows in the same survey. Our two-stage design avoids such problems.

The pre-experiment survey consisted of eight simple questions to assess the respondents' knowledge and views of fracking. ${ }^{8}$ Specifically, we asked about familiarity with fracking, such as its technical details, and familiarity with economic and environmental arguments. We also asked about the political salience of fracking and whether respondents favored or opposed it on a $1-6$

\footnotetext{
${ }^{7}$ Roughly $45 \%$ of respondents in our sample participated in the survey online, $30 \%$ responded through phone, $17 \%$ by mail, and $8 \%$ conducted the survey in person during a visit to the polling company. Individual-level and state-level covariates, for instance, a respondent's demographic information is collected whenever a person joins the TAPS respondent pool.

${ }^{8}$ The full questionnaire is in the appendix S1.
} 
scale, ranging from "strongly oppose" to "strongly support." In two open-ended questions, respondents were given the opportunity to state what they believed to be the strongest argument favoring or opposing fracking. We subsequently recorded these responses to supplement the closed-ended responses in constructing indicators of prior knowledge of specific arguments about fracking.

\subsection{Main experiment}

The main experiment took place in the April 2016 TAPS wave. ${ }^{9}$ We randomly presented respondents with information about fracking, followed by the outcome question of whether respondents favor or oppose fracking. Responses were again given a 1 - 6 scale, ranging from "strongly oppose" to "strongly support," so that our outcome variable records the level of support for fracking.

As mentioned, we cross-validated the treatments before we fielded the main experiment in two Amazon Mechanical Turk (MTurk) convenience samples in September and December 2015 for a combined sample size of 187 respondents. For each frame, we had respondents score the strength of the presented argument and whether it favors or opposes fracking. This validation exercise ensured that we used frames of comparable strength (Chong and Druckman, 2007a). It furthermore confirmed that it was easy for respondents to understand whether an argument favors or opposes fracking. ${ }^{10}$ And it helped us identify the arguments that elicited the strongest responses.

Our frames speak to arguments about fracking more generally (Hilson, 2015) and are not particular to the United States. In the current debate in England, the government takes a favorable stance over securing access to domestic energy sources, while opposing environmental groups are worried about contamination of drinking water. ${ }^{11}$ Indeed, fracking was stopped in England in 2011 after small tremors had been associated with fracking, but had just been restarted in October 2018 over significant protests. ${ }^{12}$ All these considerations and risks have been part of the debate in the United States — and our study featured them all.

Our control frame provided general information about fracking as a technique to extract oil and

\footnotetext{
${ }^{9}$ We pre-registered our experiment with egap, and a pre-analysis plan with ID 20160208AB is available from http://egap.org/registration/1724.

${ }^{10}$ See appendix S3 for further details.

11 "Fracking in the UK: What is It and Why is It Controversial?" The Guardian 15 October 2018.

12 "Anger and Blockades as Fracking Starts in UK for First Time since 2011." The Guardian 15 October 2018.
} 
natural gas. All respondents received this frame and it reads as follows:

[Control frame] Hydraulic fracturing is a drilling technique that involves injecting highly pressurized water, sand, and chemicals into tight shale rock formations underground to release oil and natural gas. As of 2013, the United States Department of Energy estimated that fracking has been used in more than 2 million oil and gas wells across the country.

Fracking is controversial mainly because it may contaminate drinking water, induce earthquakes, and divert investment away from renewable energy, which undermines the transition to a lowcarbon economy (Jackson et al., 2014; Llewellyn et al., 2015; Krupnick and Gordon, 2015). In the United States, the Environmental Defense Fund warned in a 2015 statement, "[o]ngoing physical integrity of the wells and handling the millions of gallons of wastewater coming back to the surface after fracking, over the lifetime of each well, are even bigger challenges," ${ }^{13}$ pointing to the water quality risks of fracking. In the United Kingdom, the multi-national environmental network, Friends of the Earth, currently runs a "Stop Fracking Earthquakes" campaign to raise awareness of the 57 earthquakes that were detected in Lancashire over only two months after fracking had started. ${ }^{14}$ In a political response, the mayor of neighboring Greater Manchester, Andy Burnham, formally opposed all fracking in the region, saying that fracking "is quite a radical policy." 15 Our frames are built on these concerns that find direct correspondence in the public debates on both sides of the Atlantic. We used the following texts:

[Water frame] With its large need for water, fracking not only strains water resources but also leaves behind contaminated waste water which may impact drinking water supplies. One published scientific study found evidence of drinking water contamination in a Pennsylvania county. Local air and noise pollution also occur due to heavy truck traffic to and from drilling sites.

[Uncertain consequences frame] The consequences of fracking on human health and the environment are uncertain and not well understood. However, the state of Oklahoma

\footnotetext{
13 "EDF Statement on EPA's Water Study of Hydraulic Fracturing for Oil and Gas." 4 June 2015, available at https://www.edf.org/media/edf-statement-epas-water-study-hydraulic-fracturing-oil-and-gas.

14 "Fracking and Climate Change: Stop Fracking Earthquakes" campaign, available at https://friendsoftheearth. uk/climate-change/fracking.

15 "Fracking to be Formally Opposed by all Greater Manchester Town Halls." Manchester Evening News 4 January 2019.
} 
has recently announced that fracking is most likely responsible for the sudden rise in earthquakes in that state.

[Diversion frame] Fracking diverts resources and attention from investment in solar and wind power, which have a minimal carbon footprint compared to natural gas from fracking. According to a peer-reviewed journal article, fracking delays the use and price-competitiveness of lower-carbon renewable energy.

On the other hand, fracking may generate benefits in the economy and energy sector. While effects on employment might be overstated (Kinnaman, 2011), others do find that fracking can create jobs (Weber, 2012). It also makes domestic energy markets less reliant on foreign natural resources. These potential benefits from fracking find their way into the public debate and policymaking. The Institute for 21st Century Energy, an affiliate of the U.S. Chamber of Commerce, launched a national "Shale Works for Us" campaign in 2012 "to give a voice to the U.S. businesses and industries that believe in promoting production of natural gas and oil from shale formations to boost our economy, create jobs and secure America's energy future." 16 The UK Government's official guidance document on fracking is explicit that "[s] hale gas has the potential to provide the UK with greater energy security, economic growth and jobs, and could be an important part of our transition to a low carbon future." 17 Our pro-fracking frames harness the very same arguments.

[Job creation frame] Based on a study by the consultancy firm Boston Consulting Group, fracking is estimated to have supported more than 2 million jobs already in the U.S., which pay above median salaries.

[Energy security frame] With the International Energy Agency reporting in June 2014 that the United States has become the world's largest producer of oil and natural gas, overtaking Saudi Arabia and Russia, fracking promotes the nation's energy security and energy independence.

As mentioned above, our experiment uses a full factorial design - that is, we use all possible combinations of single frames and competing counter-frames. Overall, we had 12 experimental

\footnotetext{
16 "Shale Works for Us" campaign, available at https://www.globalenergyinstitute.org/shale-works-us.

17 "Guidance on Fracking: Developing Shale Gas in the UK." Official UK Government Guidance paper, available at https://www.gov.uk/government/publications/about-shale-gas-and-hydraulic-fracturing-fracking/ developing-shale-oil-and-gas-in-the-uk.
} 


\begin{tabular}{llcllc}
\hline \multicolumn{2}{c}{ Single frames } & & & \multicolumn{2}{c}{ Counterframes } \\
$\#$ & Frame & $n$ & $\#$ & Frame & $n$ \\
\hline 1 & Control & 146 & 7 & Water + job creation & 126 \\
2 & Water & 143 & 8 & Water + energy security & 140 \\
3 & Uncertain consequences & 122 & 9 & Uncertain consequences + job creation & 142 \\
4 & Diversion & 129 & 10 & Uncertain consequences + energy security & 141 \\
5 & Job creation & 144 & 11 & Diversion + job creation & 151 \\
6 & Energy security & 150 & 12 & Diversion + energy security & 134 \\
\hline
\end{tabular}

Table 1: Experimental conditions. The full factorial design uses all possible combinations of single frames and counter-frames. Columns (1) and (2) show the experimental identifier and frame information; column(3) shows the number of respondents per condition. Full sample size, $n=1,668$.

conditions, as shown in Table 1. We randomly assigned respondents to one of these conditions and then recorded their support for fracking. For the conditions involving counter-frames, we also randomly assigned the order in which we presented the supporting and opposing arguments about fracking to avoid bias from ordering effects. The appendix shows that no such effects exist in our study. $^{18}$

\section{Results}

We present results from our study in three steps. First, we report descriptive results from our pre-experiment survey. This offers general insights into respondents' familiarity with the topic and overall support for fracking before the experiment. Second, we show the results from our experiment. Third, we study heterogeneous treatment effects in order to test hypotheses 3 and 4 .

\subsection{Descriptive results from pre-experiment survey}

In our pre-experiment survey, $77 \%$ of respondents reported they had heard about fracking, which suggests that the topic had indeed made inroads into public awareness in the United States by January 2016. ${ }^{19}$ Nonetheless, this does not necessarily translate into greater familiarity with the details. About $61 \%$ said they had moderate levels of knowledge about fracking across an index of technical, economic, and environmental details, with low knowledge (31\%) much more prevalent

\footnotetext{
${ }^{18}$ See appendix $\mathrm{S} 4$ for details.

${ }^{19}$ Full descriptive results can be found in appendix S2.
} 
than high knowledge $(8 \%)$. Somewhat less than half of the respondents were in the middle "somewhat unfamiliar" and "somewhat familiar" categories, with means estimated at 2.83 for technical knowledge, 3.10 for economic knowledge, and 3.38 for environmental knowledge, on a six-point scale.

Only one-in-five Americans thinks that fracking is not a politically salient issue, while more than a third have no opinion on issue salience. The median respondent "somewhat opposes" fracking. In general, the divisiveness of the issue in U.S. politics is evident, as $34 \%$ of the public opposes or strongly opposes fracking but one out of five Americans supports or strongly supports it. Roughly $46 \%$ do not clearly support or oppose fracking.

Interestingly, we do not find systematic differences in views toward fracking or knowledge of fracking across states with or without fracking operations underway. We grouped states into a binary variable based on whether they had gas or oil production from shale resources in 2015 using data from the U.S. Energy Information Administration. ${ }^{20}$ While fracking support across all states is lowest in Washington D.C. (mean=2.20) and highest in North Dakota and Wyoming (mean=4.50), support for fracking in states with the most shale-based production (e.g., Pennsylvania and Texas) is much closer to the overall national mean. However, public support for fracking may depend on the importance of fracking to the state economy, not necessarily total state-wide production from fracking.

In the open-ended part, we asked respondents to name the strongest argument in favor of and against fracking. In making environmental arguments, $36 \%$ mentioned water contamination; $29 \%$ said fracking has uncertain environmental consequences, such as earthquakes; and only $1 \%$ of responses highlighted that fracking diverts investment away from fracking. In support of fracking, $46 \%$ mentioned increased energy security from access to domestic energy sources and 10\% mentioned that fracking creates jobs.

\footnotetext{
${ }^{20}$ Available online from the website of the U.S. Energy Information Administration at www.eia.gov.
} 


\subsection{Main results: Effects from single frames and counter-frames}

Our first hypothesis states that the environmental risks of fracking lower support for it while the economic and energy security benefits increase support. We find evidence that is fully consistent with this expectation. Figure 1 shows estimated means and $95 \%$ confidence intervals for the control group and the five treatment conditions in which respondents received single frames. ${ }^{21}$

Relative to the control group (mean=3.32), respondents who received frames opposing fracking reported lower support. For this to happen, it did not matter if the frame emphasized water contamination $($ mean $=2.42)$, uncertain consequences from fracking $($ mean $=2.68)$, or diverting resources away from renewables (mean=2.77), support for fracking decreased. However, the relative size of the effect differed across treatments: the water treatment reduced support by $27 \%$ relative to the control group mean. The reductions from the uncertain consequences and diversion frames were smaller, but still more than $16 \%$. All reductions are statistically significant at the conventional $5 \%$ significance level.

Arguments that emphasize the opportunities that come with fracking increased support for it. These increases are also statistically significant although the effects are somewhat smaller than those from the anti-fracking frames. Relative to the control group mean, the job creation and energy security frames boosts support by roughly $13 \%-14 \%$.

These results indicate that public opinion toward fracking in the United States is malleable, yet anti-fracking frames are somewhat more effective than pro-fracking frames. The reduction in support from the strongest anti-fracking frame (i.e., water contamination) is almost twice as strong as the positive effect on fracking support from the strongest pro-fracking argument (i.e., job creation). As discussed above, a major limitation here is that the political debate regarding fracking exposes the public to frames and counter-frames and does not typically present single arguments in isolation.

Our findings show that there is an important caveat to the baseline framing hypothesis. Figure 2 shows the same information as before, but now for the experimental conditions that present competing information. Except for two conditions - when the energy security frame is combined with either

\footnotetext{
${ }^{21}$ Appendix S5 shows results with and without survey weights.
} 


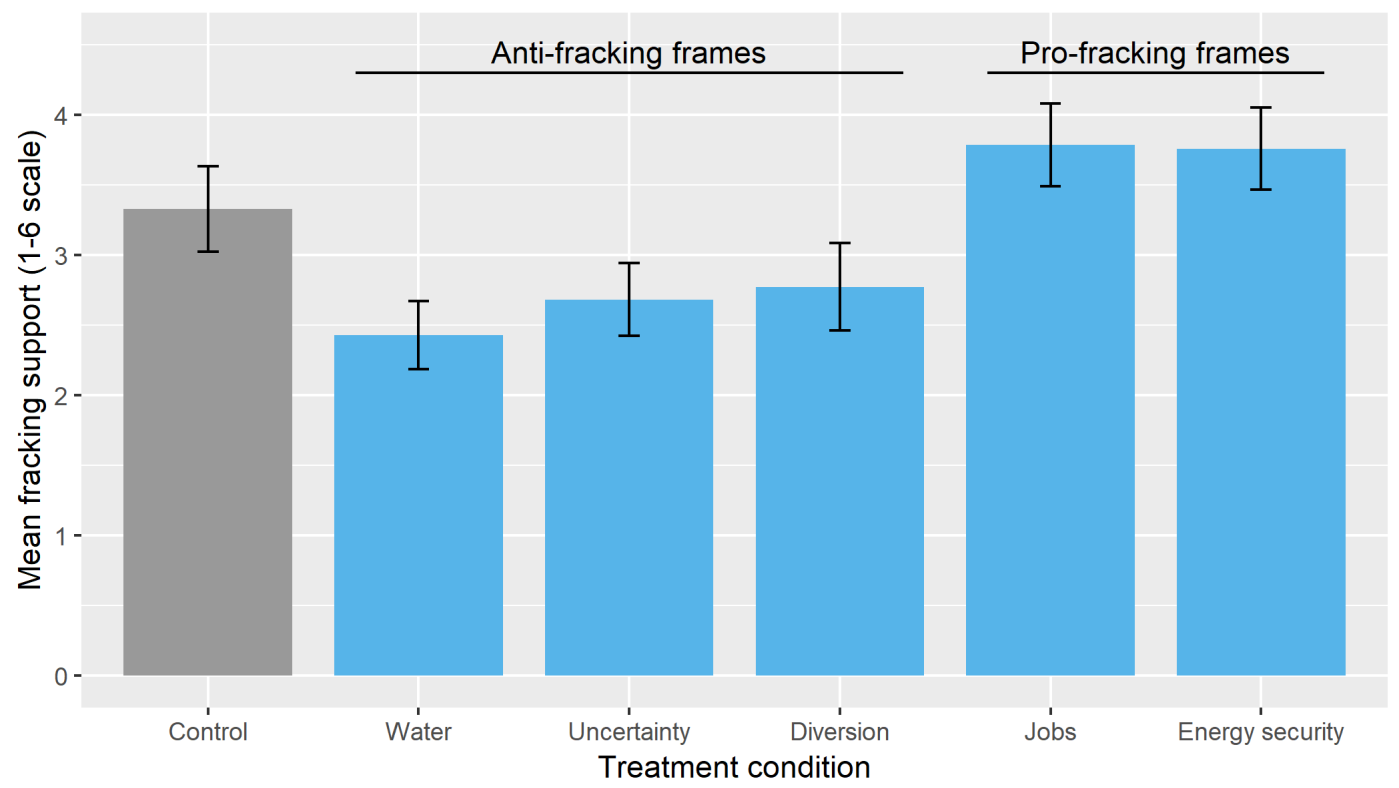

Figure 1: Treatment effects for single frame conditions. The bar plot shows estimated means and 95\% confidence intervals for fracking support in the control condition (gray bar) and all five single frame treatment conditions. Means in all five treatment conditions are statistically significantly different from the control group mean at the $5 \%$ significance level. Dependent variable: Fracking support, $1-6$, ranging from low to high support.

the water frame (condition 8 , mean $=2.60$ ) or the diversion frame (condition 12 , mean=2.88) - we do not find statistically significant changes of support in fracking relative to the control group. This offers support for our second hypothesis, according to which jointly presenting frames and counter-frames cancels the single frame effects reported before.

Although comparisons must be done with great care, fracking support decreases in all six frames that present competing information, as shown in Table 2. These reductions are generally small in size, at least for most combinations, and they do not become statistically significant. ${ }^{22}$ For the four non-significant experimental conditions, fracking support reduces by at most $7 \%$. For the two statistically significant conditions, we see reductions of $21 \%$ for the 'Water + energy security' frame and $13 \%$ for the 'Diversion + energy security'. As one would expect, reductions from these

\footnotetext{
${ }^{22}$ We used a priori power analyses to ensure that we have sufficiently large sample sizes per group to pick up medium effects (Cohen's $d=0.5$ ) without problems, so the neutralizing effects are unlikely because of insufficient statistical power. For our experimental design and to obtain an a priori power of $80 \%$ and a significance level of $\alpha=0.05$, we need 64 or 112 respondents in each group, depending on whether we correct for multiple comparisons with the conservative Bonferroni error correction. As shown in Table 1, our sample sizes are between 122-151 respondents.
} 


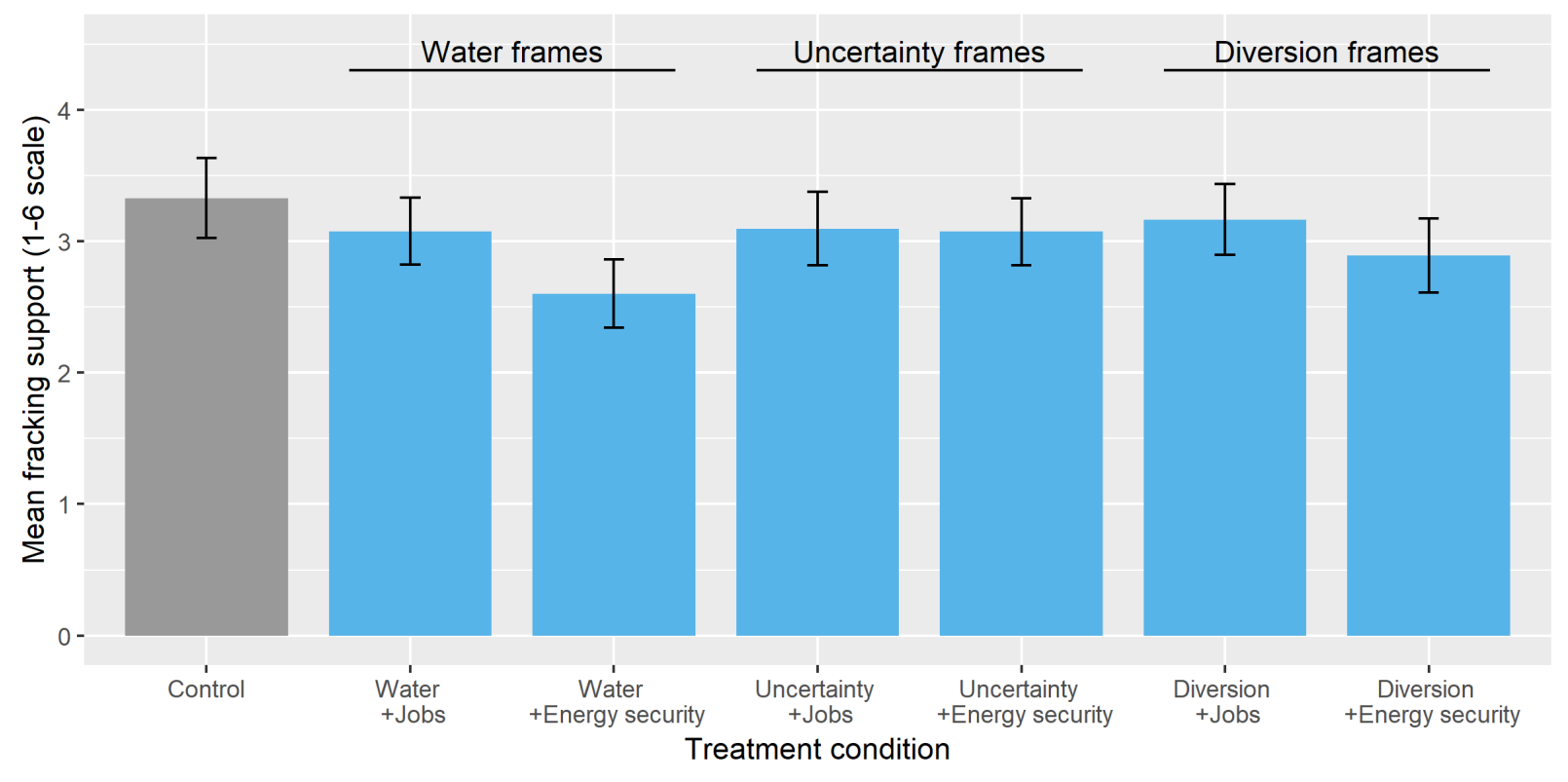

Figure 2: Treatment effects for counter-frame conditions. The bar plot shows estimated means and 95\% confidence intervals for fracking support in the control condition (gray bar) and all six counterframe treatment conditions. Only the means for the 'Water + Energy security' (condition 8) and the 'Diversion + energy security' (condition 12) are statistically significantly different from the control group mean at the 5\% significance level. Dependent variable: Fracking support, $1-6$, ranging from low to high support. 


\begin{tabular}{clccc}
\hline$\#$ & Frame & Mean & p-value & Effect size (\%) \\
\hline 1 & Control & 3.32 & - & - \\
2 & Water & 2.42 & $\mathbf{0 . 0 0 0}$ & -27.0 \\
3 & Uncertain consequences & 2.68 & $\mathbf{0 . 0 0 1}$ & -19.3 \\
4 & Diversion & 2.77 & $\mathbf{0 . 0 1 2}$ & -16.6 \\
5 & Job creation & 3.78 & $\mathbf{0 . 0 3 4}$ & +13.7 \\
6 & Energy security & 3.75 & $\mathbf{0 . 0 4 4}$ & +12.9 \\
7 & Water + Job creation & 3.07 & 0.212 & -7.5 \\
8 & Water + Energy security & 2.60 & $\mathbf{0 . 0 0 0}$ & -21.8 \\
9 & Uncertain consequences + Job creation & 3.09 & 0.270 & -6.9 \\
10 & Uncertain consequences + Energy security & 3.07 & 0.206 & -7.6 \\
11 & Diversion + Job creation & 3.16 & 0.427 & -4.8 \\
12 & Diversion + Energy security & 2.88 & $\mathbf{0 . 0 3 7}$ & -13.1 \\
\hline
\end{tabular}

Table 2: Main results by frame. Columns (3) and (4) show the estimated group mean after treatment and the associated level of statistical significance. Column (5) reports the effect size as a change in mean relative to the control group mean of 3.32. We highlight statistically significant results below the $5 \%$ significance level in bold.

combined frames are smaller in size than from the single water and diversion frames alone.

Presenting competing information, therefore, takes its toll: the effectiveness of single, one-sided frames in swaying public opinion diminishes when counter-frames are added (Chong and Druckman, 2007 a 2013). Complementing anti-fracking frames with information on potential benefits from job creation and energy security results in more favorable views relative to the opposing frames alone. Nonetheless, the risks associated with fracking seem to worry respondents more than the possible gains, even though this evidence is largely tentative.

Interestingly, although energy security appears as a strong pro-fracking single frame (which is consistent with evidence from the open-ended responses in the pre-experiment survey), it seems to become much less convincing once paired with competing information. Consistent with our second hypothesis, we find good support for counter-framing effects that can offset one-sided framing effects. These results remain reasonably strong when correcting p-values for multiple comparisons. ${ }^{23}$

\footnotetext{
${ }^{23}$ See appendix S6 for details where we report results for different p-value corrections. The p-values for our statistically significant experimental conditions for the Benjamini-Hochberg correction are as follows: Water (condition 2) $p<0.000$; Uncertainty (condition 3) $p<0.003$; Diversion (condition 4) $p<0.033$; Jobs (condition 5) $p<0.067$; Energy security (condition 6) $p<0.069$; Water + Energy security (condition 8) $p<0.000$; and Diversion + Energy security (condition 12) $p<0.067$.
} 


\subsection{Interaction results: Effect of information}

We now present results from our analysis of whether and how information about fracking may condition the main results. In order to do so, we estimate several ordinary least squares (OLS) regression models with fracking support as our dependent variable. We include state fixed-effects to account for unobserved heterogeneity across states in all our models and estimate robust standard errors.

Our third hypothesis proposes that better knowledge of fracking decreases the effectiveness of single frames and counter-frames. We subject this hypothesis to two distinct tests. ${ }^{24}$ First, we use respondents' self-reported familiarity with technical, economic, and environmental dimensions of fracking to construct conditioning variables. We create both an index across all dimensions and also use knowledge on the three dimensions separately. Second, as an alternative measure we also use non-response to open-ended questions to construct a "lack of prior knowledge" variable. The correlation between the index, based on self-reported fracking knowledge, and our non-response measure is $-0.4648, p=0.000$. All these variables come from the pre-experiment survey conducted in January 2016 and were recorded pre-treatment.

We do not find any systematic conditional effects of fracking knowledge on any of our main results. This implies that better knowledge of fracking, either in the form of an aggregated index or separately for technical, economic, or environmental knowledge, does not change any of the reported treatment effects. We therefore do not find support for our third hypothesis that framing effects would decrease with better knowledge. Fracking is a partisan, highly polarized, and informationally saturated issue, which may limit the relevance of general fracking knowledge, as the public largely responds to partisan cues (Bechtel et al., 2015; Christenson, Goldfarb, and Krinera, 2017).

Our findings paint a slightly different picture when we focus on congruent information. From the open-ended questions in our pre-experiment survey, we know for at least some respondents what they believe to be the strongest arguments supporting or opposing fracking. We use this information as a conditioning variable to examine if the treatment effect, for instance, for the water frame becomes stronger if respondents mentioned water contamination in their open-ended

\footnotetext{
${ }^{24}$ See appendix S7 for details on variables, model specification, and tabular results.
} 
responses. ${ }^{25}$ Critically, their open-ended responses were provided in the January survey, while the treatments were administered in the April experiment.

Consistent with our fourth hypothesis, we find tentative support that congruent information can amplify framing effects. In particular, we find that respondents who hold the pre-existing belief that water contamination is the biggest environmental risk from fracking do reduce their support for fracking more than other respondents. Frames that emphasize arguments that cohere with a respondent's beliefs on fracking can harden those views and trigger a stronger response: those worried about water quality who also receive the water treatment oppose fracking much more than those who only received the water treatment. This is consistent with findings that value-congruent information strengthens framing effects (Chong and Druckman, 2007a).

What is interesting is that this amplifying effect for respondents concerned with water quality extends to treatments that do not feature information on water contamination. Even when they are presented with the energy security frame, these respondents support fracking less than those with the same treatment who did not mention water contamination as the biggest environmental risk from fracking. They also tend to oppose fracking more when presented with competing information in the form of mixed frames. From a 'mental accounting' standpoint, this makes sense. When the treatment presents a respondent holding a strong pre-existing viewpoint with a pro-fracking and anti-fracking argument, this can tip the balance and break the neutralizing effect we reported above.

We find this effect only for respondents whose pre-existing concern was about water contamination. In our sample, the literature more broadly (e.g., Israel et al., 2015), and the wider policy debate (e.g., the Environmental Defense Fund's statement cited above), water contamination has repeatedly been singled out as the primary environmental threat from fracking. This makes our findings plausible, yet we cannot rule out the possibility that the null effects for other pre-existing arguments are due to a lack in statistical power. For these interaction models, we rely on openended responses from our pre-experiment survey, where water contamination was the most often mentioned single environmental concern (36\% of the times), while energy security was mentioned $47 \%$ of the times as a pro-fracking argument. ${ }^{26}$ Notwithstanding reductions in sample size, which

\footnotetext{
${ }^{25}$ See appendix $\mathrm{S} 8$ for a complete discussion and regression results.

${ }^{26}$ In total, we received 644 open-ended responses for anti-fracking arguments (38\% of sample), with 251 mentions
} 
require caution against interpreting our findings too literally for reasons of statistical power, we maintain that a key insight from our findings is the important role that specific kinds of arguments play. Rather than focusing on generic statements about benefits and costs from fracking, the specific arguments matter both in how they shape our main framing effects and how they condition our results.

Our control variables are consistent with what others have found in the literature: respondents living in fracking states and those who self-identify as Republican are more supportive of fracking; those concerned about global warming and who vote Democratic tend to oppose fracking.

\section{Conclusion}

How do people respond to competing arguments on a controversial energy issue? We study this question in the context of fracking, one of the most controversial energy policies in recent decades, not only in the United States but also in the United Kingdom. In democracies, energy policy depends on popular support, although it is only one influencing factor among others, including industrial composition and regulatory capacity (Bayer and Urpelainen, 2016; Hughes and Urpelainen, 2015). In the case of fracking, public opinion has been linked to different policy responses across U.S. states, ranging from outright bans to strong policy support (Rabe and Borick, 2013; Rinfret, Cook, and Pautz, 2014). As a salient issue, fracking has also seen substantial public participation and protests (Whitton et al., 2017), which makes the study of public opinion particularly valuable.

This paper contributes to our understanding of the relative effectiveness of different arguments on fracking in swaying public opinion. In a nationally representative survey experiment in the U.S., we presented respondents with either a pro-fracking argument, an anti-fracking argument, or both. Previous research has emphasized the importance of frames and counter-frames (Chong and Druckman, 2007a, 2013), with more recent research applying these ideas to climate and energy policy (Aklin and Urpelainen, 2013; Christenson, Goldfarb, and Krinera, 2017).

of water contamination, 201 mentions of uncertainty, and 6 mentions of diversion from renewables. For arguments in support of fracking, we had 821 observations in total (49\% of sample), with 82 mentions of job creation and 402 mentions of energy security. Numbers do not sum up as respondents also mentioned other arguments, for instance, about noise or traffic. 
Even though the heated public debate may have left the average respondent fairly well informed, we find strong framing effects. Frames that highlight water contamination, uncertain consequences from fracking, or diversion of investment away from renewables significantly decrease fracking support by between 16-27\%. Supporting frames that stress the benefits from job creation and energy security increase support by roughly $13 \%$. At the same time, providing competing information that combines positive and negative frames mostly neutralizes framing effects, yet not for all combinations of arguments. This demonstrates that the substance of frames and counter-frames that are paired to neutralize each other does matter. In our case, the job creation frame neutralizes the negative effect from water contamination, while the energy security frames does not. Studying the effect of specific arguments instead of just simple, generic frames and counter-frames helps us to understand what arguments/narratives could be effective for reframing issues (Chong and Druckman, 2013; Bernauer and McGrath, 2016). Existing research has little to say about how different arguments on the same topic shape framing effects as most research designs do not distinguish between different pro and con arguments with the same level of detail.

Our paper also adds to our understanding of how pre-existing knowledge and respondent beliefs shape framing effects on fracking. While better fracking knowledge does not condition our main framing effects, we find some tentative evidence that congruent information, especially regarding water contamination, can strengthen opposition toward fracking. The null result on fracking knowledge is not too surprising because respondents are likely to have already heard most of the arguments, especially in the run-up to the 2016 U.S. presidential election, even though they may not be able to verbalize them.

The finding on congruent information has interesting implications. Presenting respondents with information that coheres with pre-existing opinions can harden those views and trigger a stronger response. For contested issues, such as fracking, climate change, immigration, or gun control, where the general public relies on partisan cues (Bechtel et al., 2015) and elite framing (Tesler, 2018), congruent information may further polarize public opinion.

Future research should more systematically study the effects of congruent information on framing effects on politically divisive issues more generally to explore the generalizability of our results. 
Here, we recognize the special nature of the public debate on fracking. In the U.S. and globally, the issue is highly contentious, informationally saturated, polarizing, and very salient compared to many other energy policies, so these unique features need to be appreciated when interpreting our results.

In terms of policy implications, our study produces one central take-away message: successful framing and counter-framing on divisive issues where arguments in favor and against a policy exist requires targeted communication. As we have shown, the kinds of arguments matter for two reasons. First, some combinations of arguments neutralize each other while others do not; second, arguments become more powerful when they correspond to pre-existing opinions. For policymakers this results in the challenge of knowing what arguments work best with their constituency. Importantly, arguments that are effective in framing the issue in one district do not automatically travel to another district. Fracking frames need to be tailored to the local context, which is compatible with the wide variation in public opinion on the issue (Boudet et al., 2014). 


\section{References}

Aklin, Michaël, and Johannes Urpelainen. 2013. "Debating Clean Energy: Frames, Counter frames, and Audiences." Global Environmental Change 23 (5): 1225-1232.

Bayer, Patrick, and Johannes Urpelainen. 2016. "It Is All about Political Incentives: Democracy and the Renewable Feed-in Tariff." The Journal of Politics 78 (2): 603-619.

Bechtel, Michael M., Jens Hainmueller, Dominik Hangartner, and Marc Helbling. 2015. "Reality Bites: The Limits of Framing Effects for Salient and Contested Policy Issues." Political Science Research and Methods 3 (3): 683-695.

Bernauer, Thomas, and Liam F. McGrath. 2016. "Simple Reframing Unlikely to Boost Public Support for Climate Policy." Nature Climate Change 6: 680-683.

Boudet, Hilary, Christopher Clarke, Dylan Bugden, Edward Maibach, Connie Roser-Renouf, and Anthony Leiserowitz. 2014. "“Fracking" Controversy and Communication: Using National Survey Data to Understand Public Perceptions of Hydraulic Fracturing." Energy Policy 65: 57-67.

Choma, Becky L., Yaniv Hanoch, and Shannon Curriea. 2016. "Attitudes Toward Hydraulic Fracturing: The Opposing Forces of Political Conservatism and Basic Knowledge about Fracking." Global Environmental Change 38 (1): 108-117.

Chong, Dennis, and James N. Druckman. 2007a. "Framing Public Opinion in Competitive Democracies." American Political Science Review 101 (4): 637-655.

Chong, Dennis, and James N. Druckman. 2007b. "Framing Theory." Annual Review of Political Science 10: 103-126.

Chong, Dennis, and James N. Druckman. 2013. "Counterframing Effects." Journal of Politics 75 (1): 1-16.

Christenson, Dino P., Jillian L. Goldfarb, and Douglas L. Krinera. 2017. "Costs, Benefits, and the Malleability of Public Support for Fracking." Energy Policy 105: 407-417. 
Cooper, Jasper, Sung Eun Kim, and Johannes Urpelainen. 2018. "The Broad Impact of a Narrow Conflict: How Natural Resource Windfalls Shape Policy and Politics." The Journal of Politics 80 (2): 630-646.

Cosgrove, Brendan M., Daniel R. LaFave, Sahan T. M. Dissanayake, and Michael R. Donihue. 2015. "The Economic Impact of Shale Gas Development: A Natural Experiment along the New York/Pennsylvania Border." Agricultural and Resource Economics 44 (2): 20-39.

Davis, Charles. 2012. "The Politics of "Fracking": Regulating Natural Gas Drilling Practices in Colorado and Texas." Review of Policy Research 29 (2): 177-191.

Davis, Charles, and Jonathan M. Fisk. 2014. "Energy Abundance or Environmental Worries? Analyzing Public Support for Fracking in the United States." Review of Policy Research 31 (1): $1-16$.

Druckman, James N. 2004. "Political Preference Formation: Competition, Deliberation, and the (Ir)relevance of Framing Effects." American Political Science Review 98 (4): 671-686.

Evensen, Darrick, and Benjamin Brown-Steiner. 2018. "Public Perception of the Relationship between Climate Change and Unconventional Gas Development ('Fracking') in the US." Climate Policy 18 (5): 556-567.

Feyrer, James, Erin T. Mansur, and Bruce Sacerdote. 2017. "Geographic Dispersion of Economic Shocks: Evidence from the Fracking Revolution." American Economic Review 107 (4): 13131334 .

Gearhart, Sherice, Oluseyi Adegbola, and Jennifer Huemmer. 2019. "Where's the Fracking Bias?: Contested Media Frames and News Reporting on Shale Gas in the United States." Energy Research ES Social Science 51: 168-175.

Hilson, Chris. 2015. "Framing Fracking: Which Frames Are Heard in English Planning and Environmental Policy and Practice." Journal of Environmental Law 27 (2): 177-202. 
Howell, Emily L., Nan Li, Heather Akin, Dietram A. Scheufele, Michael A. Xenos, and Dominique Brossard. 2017. "How do U.S. State Residents Form Opinions about 'Fracking' in Social Contexts? A Multilevel Analysis." Energy Policy 106 (7): 345-355.

Hughes, Llewelyn, and Johannes Urpelainen. 2015. "Interests, Institutions, and Climate Policy: Explaining the Choice of Policy Instruments for the Energy Sector." Environmental Science EF Policy 54: 52-63.

IPCC. 2018. "IPCC Special Report on Global Warming of $1.5^{\circ}$ C." Available online at http://www. ipcc.ch/report/sr15/.

Israel, Andrei L., Gabrielle Wong-Parodi, Thomas Webler, and Paul C. Stern. 2015. "Eliciting Public Concerns about an Emerging Energy Technology: The Case of Unconventional Shale Gas Development in the United States." Energy Research and Social Science 8: 139-150.

Jackson, Robert B., Avner Vengosh, J. William Carey, Richard J. Davies, Thomas H. Darrah, Francis O’Sullivan, , and Gabrielle Pétron. 2014. "The Environmental Costs and Benefits of Fracking." Annual Review of Environment and Resources 39: 327-362.

Kinnaman, Thomas C. 2011. "The Economic Impact of Shale Gas Extraction: A Review of Existing Studies." Ecological Economics 70: 1243-1249.

Krupnick, Alan J., and Hal G. Gordon. 2015. "What Experts Say About the Environmental Risks of Shale Gas Development." Agricultural and Resource Economics Review 44 (2): 106-119.

Lecheler, Sophie, and Cleas H. de Vreese. 2011. "Getting Real: The Duration of Framing Effects." Journal of Communication 61 (5): 959-983.

Llewellyn, Garth T., Frank Dorman, J. L. Westland, D. Yoxtheimer, Paul Grieve, Todd Sowers, E. Humston-Fulmer, and Susan L. Brantley. 2015. "Evaluating a Groundwater Supply Contamination Incident Attributed to Marcellus Shale Gas Development." Proceedings of the National Academy of the Sciences 112 (20): 6325-6330. 
Miratrix, Luke W., Jasjeet S. Sekhon, Alexander G. Theodoridis, and Luis F. Campos. 2018. "Worth Weighting? How to Think About and Use Weights in Survey Experiments." Political Analysis 26 (3): 275-291.

Rabe, Barry G., and Christopher Borick. 2013. "Conventional Politics for Unconventional Drilling? Lessons from Pennsylvania's Early Move into Fracking Policy Development." Review of Policy Research 30 (3): 321-340.

Rinfret, Sara, Jeffrey J. Cook, and Michelle C. Pautz. 2014. "Understanding State Rulemaking Processes: Developing Fracking Rules in Colorado, New York, and Ohio." Review of Policy Research 31 (2): 88-104.

Sovacool, Benjamin K., Jonn Axsen, and Steve Sorrell. 2018. "Promoting Novelty, Rigor, and Style in Energy Social Science: Towards Codes of Practice for Appropriate Methods and Research Design." Energy Research E5 Social Science 45: 12-42.

Stokes, Leah C., and Christopher Warshaw. 2017. "Renewable Energy Policy Design and Framing Influence Public Support in the United States." Nature Energy 2: 17107.

TAPS. 2016. "The American Panel Study." Weidenbaum Center on the Economy, Government, and Public Policy at Washington University in St. Louis. For details, see http://taps.wustl.edu/ technical.

Tesler, Michael. 2018. "Elite Domination of Public Doubts About Climate Change (Not Evolution)." Political Communication 35 (2): 306-326.

Tollefson, Jeff. 2013. "Methane leaks erode green credentials of natural gas." Nature 493: 12.

U.S. Energy Information Administration. 2016a. "Hydraulic Fracturing Accounts for About Half of Current U.S. Crude Oil Production.” https://www.eia.gov/todayinenergy/detail.php?id=25372.

U.S. Energy Information Administration. 2016b. "Hydraulically Fractured Wells Provide Twothirds of U.S. Natural Gas Production." https://www.eia.gov/todayinenergy/detail.php?id= 26112. 
Weber, Jeremy G. 2012. "The Effects of a Natural Gas Boom on Employment and Income in Colorado, Texas, and Wyoming." Energy Economics 34 (5): 1580-1588.

Whitton, John, Kathryn Brasier, Ioan Charnley-Parry, and Matthew Cotton. 2017. "Shale Gas Governance in the United Kingdom and the United States: Opportunities for Public Participation and the Implications for Social Justice.” Energy Research $\&$ Social Science 26: 11-22. 